\title{
Preparation of New Solution Standards of Radium
}

\author{
W. B. Mann, L. L. Stockmann, W. J. Youden, A. Schwebel, \\ P. A. Mullen, and S. B. Garfinkel
}

\begin{abstract}
New radium-solution standards have been prepared in the ranges of 10 micrograms and also $10^{-9}$ and $10^{-11}$ gram of radium element. These have been compared with the National Bureau of Standard's 1940 and 1947 series of radium-solution standards and, as a result of these comparisons, it has been found that the $194010^{-9}$ and $10^{-11}$-gram solution standards contained some 2 to 3 percent more radium element than certified. It has been shown that this difference probably arose in the dilution of the 1940 standards.
\end{abstract}

\section{Introduction}

Radium-solution standards have previously been prepared at the National Bureau of Standards in 1940 and 1947. The 1940 series consisted of standards in the microgram range, ranging from 0.1 to $100.0 \mu \mathrm{g}$ of radium element in $5 \mathrm{ml}$ of solution, and standards for radon calibration consisting of $10^{-9}$ and $10^{-11} \mathrm{~g}$ of radium element in $100 \mathrm{ml}$ of the radium-salt and carrier solution. The 1947 series consisted only of microgram standards ranging from 0.1 to $100.0 \mu \mathrm{g}$ of radium element in $5 \mathrm{ml}$ of solution of the radium bromide and nitric acid acting as carrier.

Recently the stock of $10^{-9}$-g radium-solution standards became so depleted that it was necessary to prepare a new set of standards which has been designated as the 1957 series of standards and which consists chiefly of $10^{-9}$ and $10^{-11} \mathrm{~g}$ standards with a few microgram standards which were prepared for comparison purposes. A new set of "blank solutions" was also prepared consisting of $100-\mathrm{ml}$ samples containing 0.2 percent by weight of $\mathrm{BaCl}_{2} \cdot 2 \mathrm{H}_{2} \mathrm{O}$.

\section{Radium Calibration}

A sample of radium chloride containing approximately $10 \mathrm{mg}$ of radium element was returned to the Radium Chemical Company for a reseparation from radium D and its products and for recrystallization. It was requested that the radium salt should be crystallized in such a manner that the grain size would be of the same approximate dimensions as those in the Hönigschmid radium standards (which were also radium chloride) and that the radium salt should be enclosed in a glass tube of about the same dimensions (length, diameter, and wall thickness) as the tubes used by Hönigschmid. It would then be possible to compare this radium source with the two United States primary radium standards [1,2], ${ }^{1}$ using the NBS gold-leaf electroscope [3], without making any absorption corrections. In such a comparison the sources are supported horizontally and then gently tapped so as to spread the grains of salt uniformly along the glass tubes.

While the radium source was compared in this manner with the two primary standards, this comparison was only treated as confirmation for a series of microcalorimetric comparisons which were carried

${ }^{1}$ Figures in brackets indicate the literature references at the end of this paper. out using the NBS radiation balance $[4,5]$. These measurements consisted of three measurements of the rate of energy emission from the new radium source alone and also one triad of measurements $[1,2]$ of the new source relative to both primary standards (No. XIV and XV). The results of these measurements are shown in table 1.

TABLE 1. Radiation-balance results for comparison of new radium source with the United States primary radium standards

\begin{tabular}{|c|c|c|c|c|}
\hline \multirow{2}{*}{ Date of measurement } & \multicolumn{3}{|c|}{$\begin{array}{c}\text { Rate of energy emission in micro- } \\
\text { watts from- }\end{array}$} & \multirow{2}{*}{$\begin{array}{l}\text { Milligrams } \\
\text { of radium } \\
\text { element in } \\
\text { new source }\end{array}$} \\
\hline & No. XIV & No. XV & New source & \\
\hline $\begin{array}{l}\text { October } 23,1956 \\
\text { November } 1,1956 \\
\text { November } 8,1956 \\
\text { November } 28,1956\end{array}$ & 5728.0 & 3060.3 & $\begin{array}{l}914.8 \\
914.8 \\
914.6 \\
914.1\end{array}$ & $\begin{array}{l}6.108 \\
6.108 \\
6.107 \\
6.104\end{array}$ \\
\hline
\end{tabular}

In calculating the values shown in table 1 a correction was made for the growth of polonium-210 in the national standards since June 1934. The mean value of the rate of energy emission from the new source is $914.6 \mu \mathrm{w}$ which corresponds to $6.10_{7}$ $\mathrm{mg}$ of radium element as of November 1956. The gamma-ray comparison, carried out with the goldleaf electroscope, gave an average value from twelve measurements equal to $6.08 \mathrm{mg}$ of radium element.

\section{Preparation of the New Radium-Solution Standards}

The $6.10_{7}-\mathrm{mg}$ radium source was now completely shattered at the bottom of a 5-liter thick-bottomed glass bottle under 3.052 liters of carrier solution, determined by weighing and consisting of 0.2 -percent $\mathrm{BaCl} \cdot 2 \mathrm{H}_{2} \mathrm{O}$ plus 5 -percent $\mathrm{HCl}$, by imparting a sharp blow to the glass tube by means of a specially constructed glass rod with a thickened and elongated end which was struck at its other end with a hammer. By this procedure the master solution of radium and carrier, with a concentration of radium element of $2.001 \times 10^{-6} \mathrm{~g} / \mathrm{ml}$, was prepared.

The dilutions that were made from this master solution are shown diagrammatically in figure 1 . These dilutions were carried by two independent routes, designated as $\mathrm{A}$ and $\mathrm{B}$, in order to check the accuracy of dilution. The master solution as well as all subsequent dilutions thereof were thoroughly 
mixed by agitation before aliquots were removed. All glassware used was carefully calibrated.

First of all two 10-ml aliquots were each diluted to $100 \mathrm{ml}$ in a $100-\mathrm{ml}$ volumetric flask using carrier solution. Following this, eight 5-ml aliquots were pipetted into glass ampoules and flame-sealed. These eight ampoules each containing $10.16_{3} \mu \mathrm{g}$ of radium-226 per $5.079 \mathrm{ml}$ of solution were set aside for comparison with the microgram range of both the 1940 and 1947 standards by means of the NBS $4 \pi \gamma$-ionization chamber.

At this point the remainder of the master solution was siphoned off into two 2,500-ml volumetric flasks and flame sealed for future possible use. The remaining small volume containing the fragments of the glass tube was checked and found to contain no more radium per milliliter than one of the $10-\mu \mathrm{g}$ samples.

The further dilutions along routes $\mathrm{A}$ and $\mathrm{B}$ were carried out as shown in figure 1 and gave, by each route, fifty $10^{-9}-\mathrm{g}$ and fifty $10^{-11} \mathrm{~g}$ radium $100-\mathrm{ml}$ solution standards. Of these the first, twenty-fifth, and fiftieth $10^{-9}-\mathrm{g}$ and $10^{-11}-\mathrm{g}$ ampoules in both route $A$ and route $B$ were reserved for later com- parison with the 1940 series of $10^{-9}-\mathrm{g}$ and $10^{-11}-\mathrm{g}$ radium-solution standards. The nominal values of the dilutions shown by each route were: $2 \times 10^{-7} \mathrm{~g} / \mathrm{ml}$, $2 \times 10^{-9} \mathrm{~g} / \mathrm{ml}, 1 \times 10^{-11} \mathrm{~g} / \mathrm{ml}$, and $1 \times 10^{-13} \mathrm{~g} / \mathrm{ml}$.

Four of the eight $195710-\mu \mathrm{g}$ radium standards were now compared in the NBS $4 \pi \gamma$-ionization cham. ber $[6,7]$ with four $10-\mu \mathrm{g}$ radium-solution standards of the 1947 series and were found to agree with the 1947 values to within the \pm 1 percent estimated accuracy of the 1947 standards. Subsequently three of the 1940 series of $10-\mu \mathrm{g}$ radium-solution standards, the stock of which had been believed to be exhausted, were found and compared with three of the $10-\mu \mathrm{g}$ standards of the 1947 series and three of the 1957 series.

Due to the quite large calibration correction of the $5-\mathrm{ml}$ pipet (the volume was equal to $5.079 \mathrm{ml}$ ) the nominal $195710-\mu \mathrm{g}$ radium-solution standards have an actual radium content of $10.16_{3} \mu \mathrm{g}$. The comparisons of the 1957 standards with the 1947 standards were carried out in April and August 1957, while that of the 1957 with the $194010-\mu \mathrm{g}$ standards was carried out in August 1957.

The certified values of both the 1940 and 1947

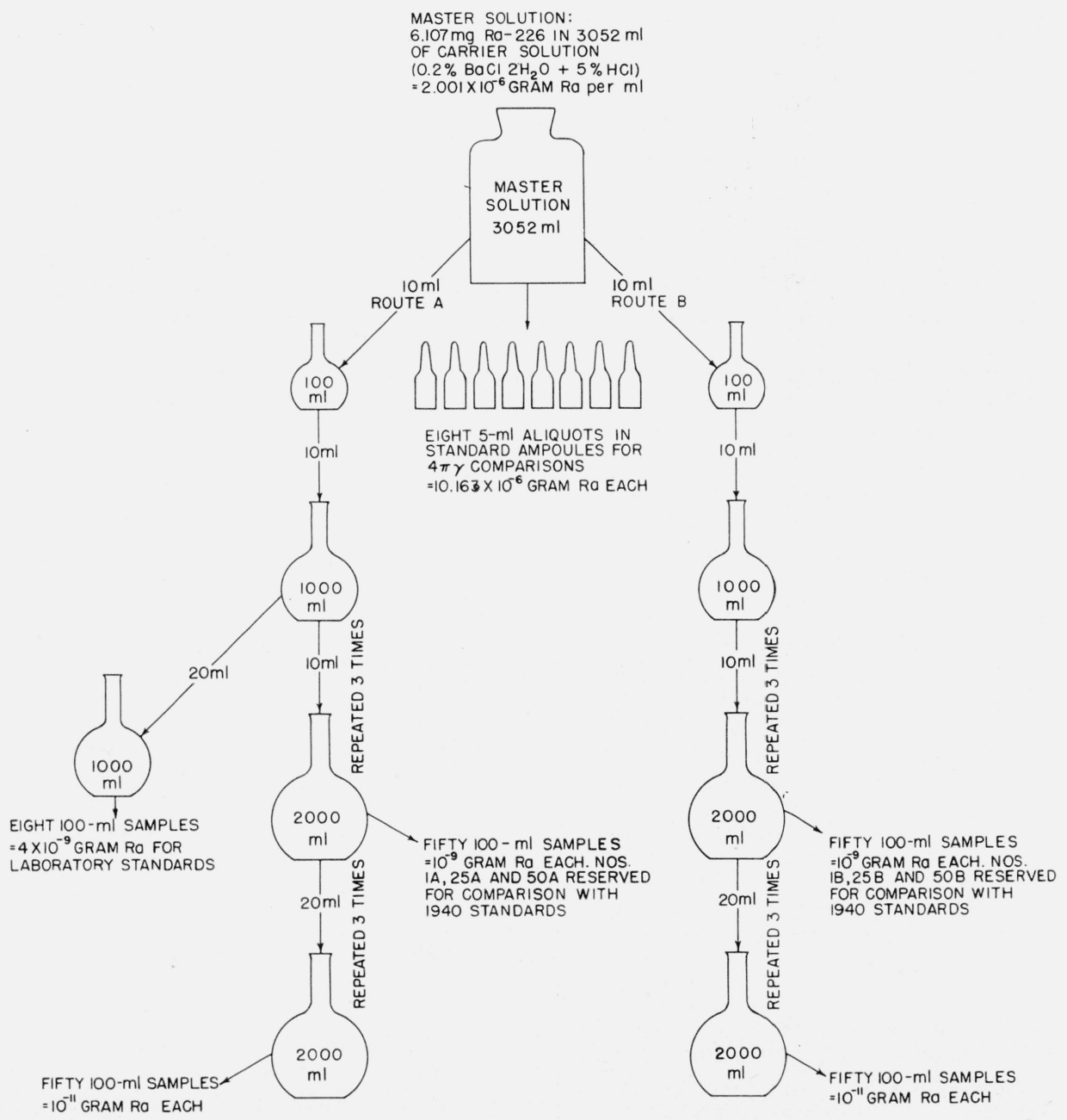

Figure 1. Dilution scheme for the preparation of $1957^{10^{-9}-g}$ and $10^{-1 *}-\mathrm{g}$ radium standards. 
" $10-\mu \mathrm{g}$ " radium-solution standards are $10 \mu \mathrm{g}$ as of August 1940 and May 1947, respectively.

In terms of the $194010-\mu \mathrm{g}$ radium standards the 1957 " $10-\mu \mathrm{g}$ " standards were found to contain 10.150 $\pm 0.0014 \mu \mathrm{g}$ of radium in August 1957. This value is in terms of different 1940 ampoules and the agreement is well within the almost \pm 1 percent uncertainty of the values of the 1940 standards.

In terms of the $194710-\mu \mathrm{g}$ radium standards the 1957 " $10-\mu \mathrm{g}$ " standards were found, in the August 1957 measurements in the NBS $4 \pi \gamma$-ionization chamber, to have a radium content of $10.230 \mu \mathrm{g}$ in contrast to the calibrated value of $10.16_{3} \mu \mathrm{g}$. This value is again within the almost \pm 1 percent uncertainty of the 1947 standards.

Finally a number of the $20-\mu \mathrm{g}$ and $50-\mu \mathrm{g}$ standards of the 1947 series were compared with those of the 1940 series. The complete series of $4 \pi \gamma$-ionizationchamber measurements is summarized in figure 2 where, on the left-hand side the results of the comparisons of the 1940 to 1947 standards are shown. In this case both the 1940 and 1947 standards are certified as 10,20 , and $50 \mu \mathrm{g}$. The small errors indicated are those to be associated with the $4 \pi \gamma$ ionization-chamber measurements while the larger errors are those inherent in both the 1940 and 1947 standards. Within these latter limits there is no deviation from unity.

On the right-hand side the ratio of the four 1957 to seven $194710-\mu \mathrm{g}$ standards is shown, after cor-recting for the volume of the $5.079-\mathrm{ml}$ pipet (used in the 1957 series) to the equivalent of the $5 \mathrm{ml}$ (i. e., correcting to $10.000 \mu \mathrm{g}$ instead of $10.16_{3} \mu \mathrm{g}$ for the 1957 series). After this correction has been made the ratio of the 1947 series (certified simply as $10 \mu \mathrm{g}$ ) to the 1957 series should be unity. Once again the deviation from unity $(1.0054 \pm 0.0004$, the error of the $4 \pi \gamma$-ionization-chamber measurement) is well within the 0.8 percent "uncertainty" certified in the case of the 1947 series of radium-solution standards above, without even considering the errors inherent in the 1957 series which are estimated to total about \pm 0.1 percent or 0.2 percent. The actual precision in

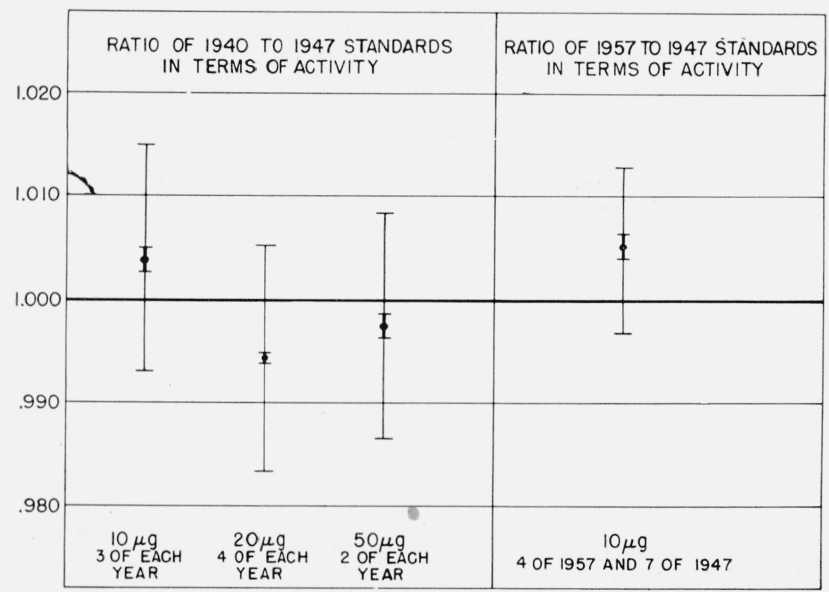

Figure 2. Comparisons of the activities of the 1940, 1947, and 1957 radium gamma-ray standards. four microcalometric comparisons of the 6-mg radium preparation with the national radium standards was such as to give a standard deviation of the average of 0.02 percent.

\section{Comparison of the 1940 and $195710^{-9}-\mathrm{g}$ Radium-Solution Standards by the Method of Radon Analysis}

The method of radon analysis in use at the $\mathrm{Na}$ tional Bureau of Standards is essentially the method described by Curtiss and Davis $[8,9]$, but with the reflux condensers for de-emanation of the radium solution standards replaced by wash bottles with sintered-glass filters as described by Harding, Schwebel, and Stockmann [10]. The radon is removed from these solutions by means of a fine stream of nitrogen bubbles passing through the solutions from the sintered-glass filters. In order to confirm the results obtained with this method of de-emanation the reflux condensers were, however, reinstalled for a final set of comparisons.

Because of the somewhat lower precision of the radon method of analysis, as compared with the gamma-ray measurements already described, a most exhaustive series of intercomparisons between the 1940 and 1957 series of standards was carried out by the radon method.

As indicated in figure 1 ampoules $1 \mathrm{~A}, 25 \mathrm{~A}, 50 \mathrm{~A}, 1 \mathrm{~B}$, $25 \mathrm{~B}$, and $50 \mathrm{~B}$ were selected from the 1957 dilutions for comparative measurements.

Four 100-ml ampoules, designated as A, B, C, and $\mathrm{D}$, were available from the $194010^{-9} \mathrm{-g}$ radiumsolution standards and were used to compare with the six 1957 ampoules.

The $194010^{-9}-\mathrm{g}$ standards were certified just as $10^{-9} \mathrm{~g}$ of radium element. The certified value for the 1957 standards is $0.999 \times 10^{-9} \mathrm{~g}$ of radium. The ratio of activities of the 1940 and 1957 standards was now determined by using each in turn to calibrate eight NBS alpha-particle-pulse-ionization chambers $[8,9]$ that are routinely used for radon assays. The results were expressed in terms of the ratio of the activity of the 1957 radium-solution standards, as determined by the calibration (in terms of counts per unit of radon) of any given chamber to that of the 1940 radium-solution standards corrected for radium decay, using the same chamber, and are shown in table 2 (a).

TABLE 2 (a). Comparison of 1957 and $194010^{-9}-g$ standards (The entries are the result of dividing the activities of the 1957 standard by those of the 1940 standards)

\begin{tabular}{|c|c|c|c|c|c|c|}
\hline \multirow{2}{*}{$\begin{array}{c}1940 \\
\text { Standards }\end{array}$} & \multicolumn{6}{|c|}{1957 Standards } \\
\hline & $1 \mathrm{~A}$ & $25 \mathrm{~A}$ & $50 \mathrm{~A}$ & $1 \mathrm{~B}$ & $25 \mathrm{~B}$ & $50 \mathrm{~B}$ \\
\hline $\begin{array}{l}\mathrm{A} \\
\mathrm{B} \\
\mathrm{C} \\
\mathrm{D}\end{array}$ & $\begin{array}{r}0.970 \\
.987 \\
.982 \\
.983\end{array}$ & $\begin{array}{r}0.964 \\
.958 \\
.969 \\
.977\end{array}$ & $\begin{array}{r}0.971 \\
.980 \\
.983 \\
.965\end{array}$ & $\begin{array}{r}0.970 \\
.974 \\
.980 \\
.980\end{array}$ & $\begin{array}{r}0.975 \\
.987 \\
.962 \\
.976\end{array}$ & $\begin{array}{r}0.974 \\
.964 \\
.964 \\
.980\end{array}$ \\
\hline
\end{tabular}

Average ratio $1957 / 1940=0.9740$

Standard deviation of the average of 24 ratios $=0.0018$ 
The average ratio of 0.9740 derived from the results of table 2 (a) for the 1957 and 1940 standards indicates that the certified radium content of the 1940 standards was low by 2.6 percent.

Subsequently eight reflux condensers were reinstalled for de-emanation of the standard solutions by boiling. The radon was fed from two of these reflux condensers into two of the eight alpha-particleionization chambers that had been used to obtain the results in table 2 (a). The values for the ratio obtained for the 1957/1940 activities (again obtained from the chamber calibrations) using the reflux condensers, and again corrected for decay, are shown in table 2 (b). These last results were not, however, used in calculating the average ratio of 0.9740 as they were not systematically determined for every combination of the 1957 standards $(1 \mathrm{~A}, 25 \mathrm{~A}, 50 \mathrm{~A}, 1 \mathrm{~B}$, $25 \mathrm{~B}$, and $50 \mathrm{~B}$ ) on the one hand and the 1940 standards $(\mathrm{A}, \mathrm{B}, \mathrm{C}$, and D) on the other. The refluxcondenser measurements were merely confirmatory.

TABle 2 (b). Comparison of 1957 and $194010^{-9}-g$ standards using reflux condensers for de-emanation

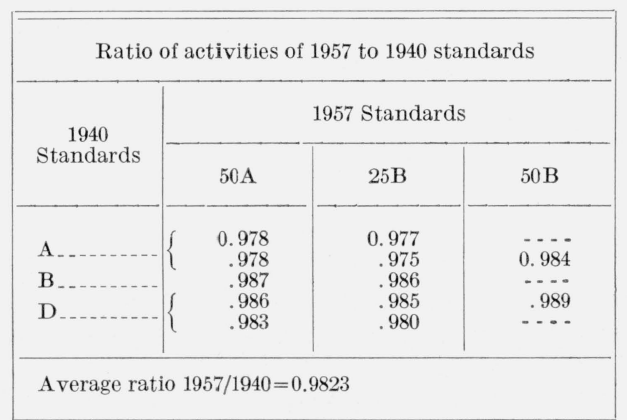

This discrepancy of 2.6 percent was so large that it was considered desirable to check the 1940 and 1957 standards against the 1947 standards to try to determine which was the more likely to be in error.

Unfortunately, however, the 1947 series consist's only of standards in the range of microgram quantities of radium element. It was, therefore, necessary to carry out a dilution of 1947-microgram standards to the $10^{-9}-\mathrm{g}$ level. This was, however, accepted as an additional check on the accuracy of our dilution. The dilution scheme is shown in figure 3, the initial master solution consisting of six $10-\mu \mathrm{g}$ radiumsolution standards from the 1947 series. By taking six standards, each consisting of $5 \mathrm{ml}$ of solution, the total error arising from the individual errors in volume of each of these standards should be proportionately lower. Once again dilutions were carried out by two alternate routes. Five samples were taken from each route and these were numbered as shown in figure 3. Again all glassware used was carefully calibrated. The nominal values of the dilutions were: $2 \times 10^{-7} \mathrm{~g} / \mathrm{ml}, 2 \times 10^{-9} \mathrm{~g} / \mathrm{ml}$, and $1 \times$ $10^{-11} \mathrm{~g} / \mathrm{ml}$.

The ratios of activities were now determined for the 1947 and $194010^{-9}-\mathrm{g}$ samples and standards

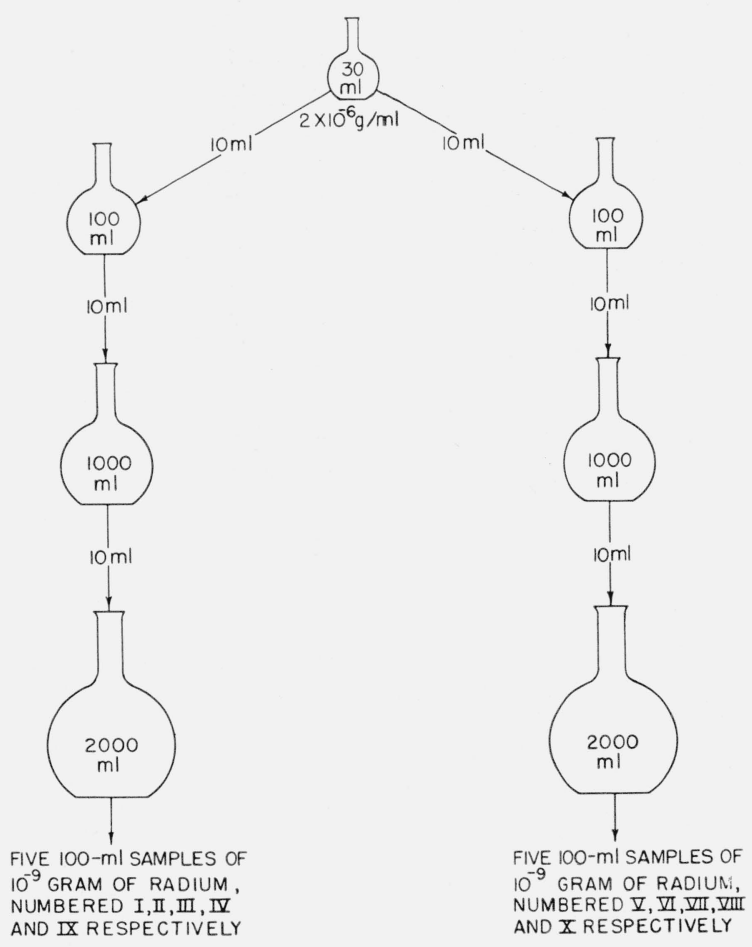

Figure 3. Dilution scheme for the preparation of $10^{-9}-\mathrm{g}$ samples from 1947 radium gamma-ray standards.

and for the 1947 and $195710^{-9}-\mathrm{g}$ samples and standards with the results shown in tables 3 (a) and 4 (a), the appropriate corrections again being made for radium decay. The sintered-glass-filter method of de-emanation was used in these measurements and also the same eight alpha-particle-ionization chambers as were used to obtain the $1957 / 1940$ ratios shown in table 2 (a). In view, however, of the greater numbers of 1940 and $195710^{-9} \mathrm{~g}$ standards and $194710^{-9}-\mathrm{g}$ samples involved it was not possible to compare every standard solution with every $194710^{-9}-\mathrm{g}$ sample. A pattern of comparison was devised, as indicated in tables 3 (a) and 4 (a) to give a maximum number of interchecks without taking every possible combination. Once again a number of spot comparisons was carried out using the same alpha-particle-ionization chambers and reflux condensers as were used to make the measurements in table 2 (b) and the results of these spot comparisons, again corrected for radium decay, are shown in tables $3(\mathrm{~b})$ and $4(\mathrm{~b})$. These results, as they were less systematic, were not used in the deriving of the $1947 / 1940$ and $1947 / 1957$ averages of 0.9722 and 0.9878 , respectively.

These results of $0.9722(1947 / 1940)$ and 0.9878 $(1947 / 1957)$, as compared with $0.9740(1957 / 1940)$, do tend to show a weight of evidence against the 1940 series of $10^{-9}-\mathrm{g}$ radium-solution standards. 
TABLE 3 (a). Comparison of $1947 \quad 10^{-9}-\mathrm{g}$ samples and 1940 $10^{-9}-g$ standards

(The entries are the result of dividing the activities of the 1947 samples by those of the 1940 standards)

\begin{tabular}{|c|c|c|c|c|c|c|c|c|}
\hline \multirow{2}{*}{$\begin{array}{l}1940 \\
\text { Standards }\end{array}$} & \multicolumn{8}{|c|}{$\begin{array}{l}10^{-9} \text {-g solutions made from six } 194710-\mu \text { g gamma-ray } \\
\text { standards }\end{array}$} \\
\hline & I & II & III & IV & $\mathrm{V}$ & VI & VII & VIII \\
\hline $\begin{array}{l}\mathrm{A} \\
\mathrm{B}_{\mathrm{n}} \\
\mathrm{C} \\
\mathrm{D}\end{array}$ & $\begin{array}{r}0.976 \\
-967 \\
. .-\end{array}$ & $\begin{array}{r}0.966 \\
.972 \\
.97\end{array}$ & $\begin{array}{l}0.970 \\
.978\end{array}$ & $\begin{array}{l}0.980 \\
.972\end{array}$ & $\begin{array}{r}0.967 \\
.981 \\
\ldots \ldots\end{array}$ & $\begin{array}{r}0.973 \\
.970 \\
\ldots . .\end{array}$ & \begin{tabular}{l}
0.967 \\
\hdashline .2 \\
.981
\end{tabular} & $\begin{array}{r}0.956 \\
.980\end{array}$ \\
\hline
\end{tabular}

A verage ratio $1947 / 1940=0.9722$

Standard deviation of the average of 16 ratios $=.0018$

TABLE 3 (b). Comparison of $1947 \quad 10^{-9}-g$ samples and 1940 $10^{-9}-g$ standards using reflux condensers for de-emanation

\begin{tabular}{|c|c|c|c|c|}
\hline \multicolumn{5}{|c|}{ Ratio of activities of 1947 to 1940 standards } \\
\hline \multirow[t]{2}{*}{1940 Standards } & \multicolumn{4}{|c|}{$\begin{array}{l}10^{-9}-\mathrm{g} \text { solutions made from six } 1947 \text { gamma-ray } \\
\text { standards }\end{array}$} \\
\hline & I & II & $\mathrm{V}$ & VIII \\
\hline A & 0.966 & 0.960 & 0.962 & 0.965 \\
\hline B ... & .981 & .975 & .976 & .968 \\
\hline D.... & .974 & .968 & .970 & .978 \\
\hline & .977 & .973 & .969 & .970 \\
\hline
\end{tabular}

A verage ratio $1947 / 1940=0.9702$

TABLE 4 (a).-Comparison of $1947 \quad 10^{-9}-g$ samples and $195 \%$ $10^{-9}-g$ standards (the entries are the result of dividing the activities of the 1947 samples by those of the $195 \%$ standards)

\begin{tabular}{|c|c|c|c|c|c|c|c|c|}
\hline \multirow{2}{*}{$\begin{array}{c}1957 \\
\text { Standards }\end{array}$} & \multicolumn{8}{|c|}{$10^{-9}-\mathrm{g}$ solutions made from six 1947 gamma-ray standards } \\
\hline & I & II & III & IV & V & VI & VII & VIII \\
\hline $1 A_{-}$ & 0.990 & 0.979 & 0.991 & 0.984 & ..... & & $\ldots$. & ...... \\
\hline $25 \mathrm{~A}$ - & $-\ldots$ & $\ldots$. & .987 & 1.008 & 1.007 & 0.987 & $\ldots$ & -.... \\
\hline $50 \mathrm{~A}$. & $\ldots$ & $\ldots$ & $-1-$ & $-1 .$. & 0.993 & .988 & 0.974 & 0.984 \\
\hline 1B & $\cdots$ & ....... & .989 & 0.986 & $\ldots$. & -.... & .981 & .982 \\
\hline $25 B_{\ldots} \ldots$ & .990 & .986 & .... & -.... & .990 & .983 & .... & - . . \\
\hline $50 \mathrm{~B}$ & .993 & .982 & ..... & $\ldots$ & $\ldots$ & ..... & .988 & .984 \\
\hline
\end{tabular}

Average ratio $1947 / 1957=0.9878$

Standard deviation of the average of 24 ratios $=0.0014$

TABLE 4 (b).-Comparison of $1947 \quad 10^{-9}-g$ samples and 1957 $10^{-9}-g$ standards using reflux condensers for de-emanation

\begin{tabular}{|c|c|c|c|c|}
\hline \multicolumn{5}{|c|}{ Ratio of activities of 1947 to 1957 standards } \\
\hline \multirow{2}{*}{1957 Standards } & \multicolumn{4}{|c|}{$\begin{array}{l}10^{-9} \text {-g solutions made from six } 1947 \text { gamma-ray } \\
\text { standards }\end{array}$} \\
\hline & I & II & $\mathrm{V}$ & VIII \\
\hline $50 \mathrm{~A}_{-}$ & 0.988 & 0.990 & 0.984 & 0.986 \\
\hline $25 \mathrm{~B}$ & $\begin{array}{r}.993 \\
0.996\end{array}$ & 0.983 & 0.988 & 0.989 \\
\hline $50 \mathrm{P}$ & $\begin{array}{r}.989 \\
0.987\end{array}$ & .993 & .985 & ...... \\
\hline $50 \mathrm{~B}$ & 0.987 & 0.984 & $\ldots$ & 0.980 \\
\hline
\end{tabular}

Average ratio $1947 / 1957=0.9885$
The direct measurements of the ratios for the standards and samples for the different years are therefore:

$$
\begin{aligned}
& 1947 / 1940=0.9722 \\
& 1940 / 1957=1.0267 \\
& 1957 / 1947=1.0124
\end{aligned}
$$

$$
\begin{aligned}
& 1940 / 1947=1.0286 \\
& 1957 / 1940=0.9740 \\
& 1947 / 1957=0.9878
\end{aligned}
$$

Product of 3 ratios $=1.0124$

$$
=0.9896^{2}
$$

The three estimates, if completely consistent, should multiply together to give exactly unity. The slightly less than 1-percent uncertainty in the individual ratios accounts for this discrepancy.

The three estimates may be slightly adjusted by a least-squares technique to give estimates that are consistent. For example, in addition to the direct estimate of the $1957 / 1947$ ratio (1.0124) an indirect estimate may be obtained by multiplying the estimate for $1957 / 1940$ by the estimate for $1940 / 1947$. The result of multiplying 0.9740 by 1.0286 is 1.0019 . Most weight must be given the directly obtained value of 1.0124. The proper average is obtained by taking the cube root of the product of the square of the directly observed ratio by the indirectly estimated ratio for $1957 / 1947$. Thus

$$
\sqrt[3]{1.0124 \times 1.0124 \times 1.0019}=1.0089 .
$$

The adjusted estimates of the ratios between standards and samples for different years, obtained by this least squares technique are:

$$
\begin{aligned}
& 1947 / 1940=0.9688 \\
& 1940 / 1957=1.0231 \\
& 1947 / 1947=1.0089
\end{aligned}
$$$$
\begin{aligned}
& 1940 / 1947=1.0322 \\
& 1957 / 1940=0.9774 \\
& 1947 / 1957=0.9912
\end{aligned}
$$

Product of 3 ratios $=1.0000$

$$
=1.0000
$$

The adjustments do not exceed twice the estimated standard deviation in the direct estimates of the ratios. The standard deviation of the average ratios listed in tables 2,3 , and 4 is slightly less than 0.2 percent. These adjusted values combine all the evidence and are the preferred ratios.

\section{Comparison of the 1940 and $195710^{-11}-\mathrm{g}$ Radium-Solution Standards by the Method of Radon Analysis}

As a further check between the 1940 and 1957 series of standards three $194010^{-11}$-g radium-solution standards of $100 \mathrm{ml}$, certified as containing $1.025 \times$ $10^{-11} \mathrm{~g}$ and designated as 11,12 , and 13 , were compared with three $1957 \quad 10^{-11}-\mathrm{g}$ radium-solution standards of $100 \mathrm{ml}$, designated as 21,22 , and 23 and found to contain $1.001 \times 10^{-11} \mathrm{~g}$, by the method of radon analysis using alpha-particle-ionization chambers 7 and 12 and de-emanating by boiling in the reflux condensers.

In view of the longer collection times that were involved and the fact that the readings were only some ten times background the results took much

2 The reciprocals of the ratios as determined from the original values are shown for convenience in computation, should they be desired. 
longer to obtain and it was not, therefore, possible to carry out as exhaustive comparisons as with the $10^{-9}$-g standards. The results, after correction for radium decay, are shown, however, in table 5 . The average ratio of $0.986(1957 / 1940)$, with a standard deviation of the average of 0.020 , is in fairly close agreement with the value of 0.9774 (1957/1940) for the adjusted ratio for the $10^{-9}-\mathrm{g}$ radium-solution standards. It must, however, be borne in mind that additional errors are introduced at such low concentrations as $10^{-11}$-g radium per $100 \mathrm{ml}$ by uncertainties in the radium content of the diluting carrier solution, as will be apparent from measurements made on such solutions which will now be described.

TABLE 5. Comparison of 1959 and $1940 \quad 10^{-11} \mathrm{~g}$ standards using reflux condensers for de-emanation

\begin{tabular}{|c|c|c|}
\hline \multirow{2}{*}{ Standard No.a } & \multicolumn{2}{|c|}{ Radium content in units of $10^{-11} \mathrm{~g}$} \\
\hline & Chamber No. 7 & Chamber No. 12 \\
\hline $11 \ldots$ & 1. 040 & -.... \\
\hline 21. & 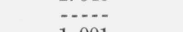 & 1. 032 \\
\hline $\begin{array}{ll}12 \ldots \\
22\end{array}$ & 1.001 & 1.016 \\
\hline $11 \ldots$ & -....- & 1.047 \\
\hline 21. & 1. 022 & $\ldots$ \\
\hline 12 & 1.032 & 1. 007 \\
\hline $\begin{array}{l}13-- \\
23-\end{array}$ & 1.052 & 0.990 \\
\hline $13 \ldots$ & $\cdots-\cdot$ & 1. 018 \\
\hline $23 \ldots$ & $\begin{array}{l}1.012 \\
0.987\end{array}$ & -..... \\
\hline $\begin{array}{l}\text { A verage ratio } 1957 / 1940=0.986 \\
\text { Standard deviation }=0.020\end{array}$ & & \\
\hline
\end{tabular}

a 1940 Standards designated as 11,12 , and $13 ; 1957$ Standards designated as 21 , 22 , and 23

\section{Determination of the Radium Content of the Carrier Solution}

The carrier solution used in the dilutions, shown schematically in figures 1 and 3 , consisted of 0.2 percent by weight of $\mathrm{BaCl}_{2} \cdot 2 \mathrm{H}_{2} \mathrm{O}$. In order to determine the radium content of this carrier solution, $31 \mathrm{~g}$ of the barium chloride used in its preparation was dissolved in $100 \mathrm{ml}$ of radium-free distilled water and this solution was then analyzed for radium by the radon method. Three measurements of this sample gave values of $0.1245,0.1258$, and $0.1261 \times$ $10^{-12} \mathrm{~g}$, or an average of $0.1255 \times 10^{-12} \mathrm{~g}$, radium per gram of $\mathrm{BaCl}_{2} \cdot 2 \mathrm{H}_{2} \mathrm{O}$. Thus a $100-\mathrm{ml}$ sample of the 0.2 percent by weight barium chloride carrier solution would contain a total of $0.025 \times 10^{-12} \mathrm{~g}$ of radium.

There is no record of the method of measuring the 1940 blank solutions certified as containing $0.25 \times$ $10^{-12} \mathrm{~g}$ of radium per $100 \mathrm{ml}$. Attempts were made, however, to measure by the radon method the radium content of both 1940 and 1957 blank solutions. These attempts resulted in a wide range of values being obtained, some of which were as much as ten times greater, in the case of the 1957 blank solutions, than the value obtained from the measurements of the nearly saturated solution of barium chloride.

These variations reflect the limitations of the radon method for measurements which are, in this case, of the order of one-tenth background. The average value obtained, however, for the 1940 blank solutions was $0.18 \times 10^{-12} \mathrm{~g}$ of radium per $100 \mathrm{ml}$ as compared with the certified value of $0.25 \times 10^{-12} \mathrm{~g}$ of radium per $100 \mathrm{ml}$.

It appears that the $194010^{-11} \mathrm{~g}$ radium-solution standards which are certified as containing $1.025 \times 10^{-11} \mathrm{~g}$ of radium were derived from the dilution of the $10^{-9}-\mathrm{g}$ radium solution, certified as containing $10^{-9} \mathrm{~g}$ of radium per $100 \mathrm{ml}$, with the blank solution which was said to contain $0.025 \times 10^{-11} \mathrm{~g}$ of radium per $100 \mathrm{ml}$. If this last figure were obtained, however, by the radon method it would appear to be no more reliable than that of $0.18 \times 10^{-12} \mathrm{~g}$ of radium per $100 \mathrm{ml}$ recently determined.

Under these circumstances the value of 0.986 obtained for the ratio of the $1957 / 194010^{-11} \mathrm{~g}$ radium solution standards cannot be said to differ significantly from that of 0.977 obtained for the ratio of the $1957 / 1940 \quad 10^{-9}-\mathrm{g}$ radium-solution standards.

\section{Summary}

From the measurements on the 1940 and 1957 $10^{-9}-\mathrm{g}$ radium-solution standards, which are confirmed by those of the $10^{-11} \mathrm{~g}$ series, it would appear that there is an error of about 2.6 percent in the 1940 series of $10^{-9}-\mathrm{g}$ and $10^{-11}-\mathrm{g}$ radium-solution standards. As no corresponding discrepancy has been observed in the microgram series of standards it is assumed that the error is one which occurred in the dilution down to $10^{-9} \mathrm{~g}$ and $10^{-11} \mathrm{~g}$ per $100 \mathrm{ml}$ in 1940 .

\section{References}

[1] T. I. Davenport, C. C. MeCraven, W. B. Mann, and C. C. Smith, Comparison of four national radium standards, Part 1. Experimental procedures and results; W. S. Connor and W. J. Youden, Part 2. Statistical procedures and survey, J. Research NBS 53, 267 (1954) RP2544.

[2] T. P. Loftus, W. B. Mann, L. Paolella, L. L. Stockmann, and W. J. Youden, Comparisons of national radium standards, J. Research NBS 58, 169 (1957) RP2749.

[3] L. F. Curtiss, A projection electroscope for standardizing radium preparations, Rev. Sci. Instr. 16, 363 (1928).

[4] W. B. Mann, Use of Callendar's "radio-balance" for the measurement of energy emission from radioactive sources, J. Research NBS 52, 177 (1954) RP2486.

[5] W. B. Mann, A radiation balance for the microcalorimetric comparison of four national radium standards, J. Research NBS 53, 277 (1954) RP2545.

[6] C. C. Smith and H. H. Seliger, Improvement in response of $4 \pi$-gamma-ionization chambers, Rev. Sci. Instr. 24, 474 (1953).

[7] S. B. Garfinkel, Semi-automatic Townsend Balance system (submitted for publication).

[8] L. F. Curtiss and F. J. Davis, A counting method for the determination of small amounts of radium and radon, J. Research NBS 31, 181 (1943) RP1557.

[9] F. J. Davis, Factors affecting operation of apparatus for counting alpha particles in an ion counting chamber, J. Research NBS 39, 545 (1947) RP1846.

[10] J. E. Harding, A. Schwebel, and L. L. Stockmann, Report on the determination of small amounts of radium in solution, AOAC 41, 311 (1958).

Washington, August 8, 1958. 